\title{
Antinomias entre a luta de classes e a formação humana: a educação enquanto locus de resistência
}

\author{
Antinomias entre la lucha de clases y la formación humana: la educación \\ como locus de resistencia
}

\section{Antinomies between class struggle and human development: education as a locus of resistance}

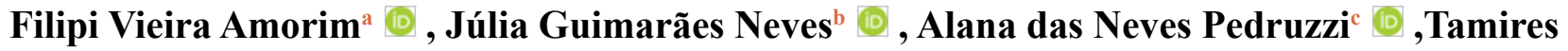 Lopes Podewils ${ }^{\mathrm{d}}$ (@) Ricardo Gauterio Cruz ${ }^{\mathrm{e}}$}

${ }^{a}$ Doutor em Educação Ambiental (PPGEA-FURG). Professor Adjunto no Instituto de Educação, área de Filosofia, da Universidade Federal do Rio Grande - FURG, Rio Grande/RS, Brasil. Endereço institucional: Universidade Federal do Rio Grande - FURG, Instituto de Educação - IE. Av. Itália, km 8, Prédio 4. Bairro Carreiros, Rio Grande/RS, Brasil. E-mail: filipi_amorim@yahoo.com.br. ${ }^{\mathrm{b}}$ Doutora em Educação pelo Programa de Pós-Graduação em Educação da Universidade Federal de Pelotas - UFPEL. E-mail: julianeves@hotmail.com

' Doutora em Educação Ambiental (PPGEA-FURG). Professora Adjunta no Instituto de Educação, área de Filosofia, da Universidade Federal do Rio Grande - FURG, Rio Grande/RS, Brasil. E-mail: alanadnp@gmail.com

${ }^{d}$ Doutora em Educação Ambiental (PPGEA-FURG). Professora Adjunta no Instituto de Educação, área de Filosofia, da Universidade Federal do Rio Grande - FURG, Rio Grande/RS, Brasil. E-mail: podewils.t@gmail.com

${ }^{e}$ Administrador no Instituto Federal Sul-Rio-Grandense - IFSul, Pelotas/RS, Brasil Doutor em Educação Ambiental (PPGEA-

-FURG). E-mail: ricardo_gcruz@hotmail.com.

Resumo: O objetivo é problematizar a Educação enquanto locus de resistência, na interlocução com a Pedagogia do Oprimido. Defende-se a Educação enquanto sinônimo de Formação Humana; sob o princípio de ultrapassar o sentido desta como mero substantivo, concebem-na como verbo do quefazer humano e adjetivo da convivência e do destino coletivo da humanidade; possibilidade concreta para a realização de interesses coletivos em detrimento dos individuais, sem restringir a liberdade do indivíduo. Da primeira aproximação com a Pedagogia do Oprimido, trata-se da necessidade de uma Educação radical, com a metáfora da raiz pivotante, que defende as técnicas educativas como processos e não como finalidades mercadológicas e servis que prezam pela manutenção da opressão humana. O leitor encontrará

Como citar o artigo: AMORIM, Filipi Vieira; NEVES, Júlia Guimarães; PEDRUZZI, Alana das Neves; PODEWILS, Tamires Lopes; CRUZ, Ricardo Gauterio. Antinomias entre a luta de classes e a formação humana: a educação enquanto locus de resistência. Revista de Ciências Humanas, Florianópolis, v. 53, 2019 DOI: 10.5007/2178-4582.2019.e44985 você pode compartilhar, adaptar, para qualquer fim, desde que atribua a autoria da obra, forneça um link para a licença, e indicar se foram feitas alterações. 
neste texto o diálogo entre a ética, as teorias e as metodologias do ensino-aprendizagem, e as aproximações destas com a prática do educador e da educadora preocupados com a transformação social.

Palavras-chave: Educação; Formação Humana; Paulo Freire; Ética.

Resumen: El objetivo es problematizar la Educación como locus de resistencia, en diálogo con la Pedagogía del Oprimido. Se defiende la Educación como sinónimo de Formación Humana, bajo el principio de superar su significado como un mero sustantivo, concibiéndola como verbo del quehacer humano y adjetivo de coexistencia consciente acerca de los designios y del destino colectivo de la humanidad, posibilidad concreta para la realización de intereses colectivos en detrimento de los egoísmos personales, sin restringir la libertad del individuo. El primer acercamiento a la Pedagogía del Oprimido es la necesidad de una Educación radical, con la metáfora de la raíz pivotante, que defiende las experiencias educativas como procesos y no como fines comerciales y serviles que valoran el mantenimiento de la opresión humana. El lector encontrará en este texto el diálogo entre la ética, teorías y metodologías de enseñanza y aprendizaje, y las aproximaciones con la práctica del educador y de la educadora preocupados por la transformación social.

Palabras clave: Educación; Formación Humana; Paulo Freire; Principio moral.

\begin{abstract}
The aim is to problematize Education as a locus of resistance in dialogue with the Pedagogy of the Oppressed. Here Education is defended as a synonym for Human Development; under the principle of surpassing its meaning as a mere noun, conceiving it as a verb for human action and as an adjective for coexistence and the collective destiny of humanity; concrete possibility for the realization of collective interests at the expense of individual ones, without restricting the individual's freedom. The first approach to the Pedagogy of the Oppressed is the need for a radical Education, with the metaphor of the pivoting root, which defends educational techniques as processes and not as marketable and servile purposes that value the maintenance of human oppression. The reader will find in this text a dialog between ethics, teaching-learning theories and methodologies, and their approximations with the practice of the educator concerned with social transformation.
\end{abstract}

Keywords: Education; Human Formation; Paulo Freire; Ethics.

\title{
1 INTRODUÇ̃̃̃O
}

Não há realidade histórica [...] que não seja humana. Não há história sem homens, como não há uma história para os homens, mas uma história de homens que, feita por eles, também os faz (FREIRE, 2016, p. 204).

Não há como caracterizar uma discussão que queira legitimar a Educação enquanto locus de resistência, tal como nos propomos, sem a assumida consciência de que muito tem sido dito sobre esta temática, basta conferirmos as discussões tematizadas por pesquisadores da área (FLEURI, 1989; PALUDO, 2001; PONTUAL \& IRELAND, 2006; BRANDÃO, 2006; STRECK \& ESTEBAN, 2013; entre outros). As discussões ultrapassam o espaço acadêmico, uma vez que a temática educacional ganha voz e ouvidos em amplos setores da sociedade. Assim, tanto na esfera pública quanto na dimensão privada, a Educação vem se constituindo como um campo de lutas e de disputas ideológicas.

Portanto, ocorre que essa ampliação em torno do debate não está isenta das intencionalidades que permeiam as modas e os modos de vida estabelecidos nas interações sociais (econômicas, políticas e culturais) contemporâneas. É neste sentido que as perguntas que orientarão a nossa discussão são advogadas, em torno de considerações que permeiam a porosidade dos laços humanos: Para que serve a Educação? Que locus é esse? Por que razões falaremos aqui de resistência?

Nossa primeira proposição é resgatar a obra Pedagogia do Oprimido, do educador Paulo Freire (1921-1997), como mediadora de uma proposta indissociável entre ética e epistemologia, política e pedagogia, filosofia e educação para uma abordagem teórico-reflexiva sobre os processos de ensino e 
aprendizagem. Os interesses de tal proposta buscam atender exigências não tão novas, mas esquecidas no mundo globalizado em que predominam ações e políticas de um desenvolvimento neoliberal: individualista, classista, desigual e opressor. Além disto e sobretudo, a discussão se faz atual por conta da fase política em que vive o Brasil pós-impeachment, onde uma série de conquistas e direitos sociais estão ameaçadas e a Classe Trabalhadora está a temer o retrocesso.

Neste horizonte de incertezas, a nossa ênfase quer resgatar os elementos constitutivos da Pedagogia do Oprimido em nome da legitimação da Educação como locus de resistência ao fatalismo ideológico que fortalece as desigualdades e as explorações do humano pelo humano. Queremos reafirmar a necessidade de uma Educação ocupada com o bem comum, em nome das possibilidades viáveis do "ser mais" (FREIRE, 2014a; 2014b). Pela escolha da Pedagogia do Oprimido como mote referencial deste ensaio, é importante dizer que reconhecemos a presença contínua de abordagens de mesmo teor em outras obras de Paulo Freire - sempre preocupado com as questões sobre a existência humana -, mas, em função da necessidade de um recorte, acreditamos que esta obra comporta, em especial, uma discussão abrangente sobre algumas das antinomias entre a luta de classes e a formação humana, tal e qual prevê o nosso título.

Educação (com "E" maiúsculo) nada mais é do que uma especificidade humana. É um dos caminhos pelos quais a sociedade alicerça, (re)avalia, (re)cria, (re)produz e (re)inventa os seus valores, seus saberes, suas crenças e suas representações coletivas. Nesta perspectiva, a palavra Educação, tanto em sua abstração conceitual quanto em seu sentido concreto e material, não cabe no stricto arcabouço da educação (esta, com "e" minúsculo) formal, da escola, da universidade, dos espaços institucionalizados, da escolarização, enfim.... Obviamente, educação é parte da Educação, mas não necessariamente Educação é o todo da educação.

Educação (com “E” maiúsculo) é sinônimo de Formação Humana, isto é, representa uma dimensão ontológica, independente da forma social que esta toma em cada período histórico. A Formação Humana perpassa os mais variados contextos sociais (econômicos, políticos e culturais), por isso não pode ser delimitada pelas fronteiras de um espaço finito e cercado de limites. Compreender a Educação, enquanto sinônimo de Formação Humana, exige-nos que consideremos os diferentes contextos da racionalidade prática, da ética e do ethos, da tomada consciente de decisões cotidianas e de escolhas emancipatórias. Sem ressalvas, a Educação, como defendemos, faz parte do envolvimento ativo entre os sujeitos que trilham objetivos em nome do bem comum e da coletividade.

Se falamos em bem comum, falamos de coletividade. Ocorre que, se há bem comum, há, antagonicamente, interesses individuais calcados na perspectiva do liberalismo moderno: concorrencial; baseado na falácia de uma igualdade meritocrática de direitos; catapulta para a desigualdade social; e que apresenta a soma dos interesses individuais como se fosse uma expressão do bem comum. Esse bem para o individualismo refere-se aos ideais e intencionalidades de uma tendência que não compactua com princípios éticos de solidariedade e fraternidade, intrínsecos ao campo das relações humanas.

No diálogo com a Pedagogia do Oprimido, buscamos elementos que amparem nossa crença de que a Educação só é legítima quando busca concretizar a realização de interesses coletivos. Logo, trata-se do sinônimo de Formação Humana, como afirmamos algures. Falar de interesses coletivos significa assumir um posicionamento político em relação à Educação, elemento que escapa à educação (com "e" minúsculo), pois esta última tem se apresentado como base de fortalecimento dos ideais da sociedade cindida em classes antagônicas.

Ora, se a Pedagogia do Oprimido fosse um oráculo e perguntássemos se é possível uma Educação (com "E" maiúsculo, lembremos) para o bem comum, dentro de uma sociedade de classes que visa o bem individualista, o que leríamos no ecrã? Sem dúvidas, a resposta seria não!

Daí que a educação impera, hoje, nas operações de uma racionalidade instrumental voltada às exigências do mercado de trabalho. A educação perpetua a reprodução das ideias sobre as quais se alicerça a reprodução social da desigualdade e da exploração. Em uma análise política destas afirmações, 
constatamos que o objetivo de tal tendência é suprir as necessidades do mundo globalizado. $\mathrm{O}$ foco principal da educação está no ensino que visa o treinamento e o adestramento para que sejam sanadas as exigências do mercado de trabalho e mantido o disciplinamento do indivíduo para a vida social sob a égide concorrencial. Assim, visualizamos que a educação não serve aos ideais da solidariedade e da ética humana, mas tem transformado o próprio ser humano em um ser de mendicidade ao mercado de trabalho para a manutenção e a reprodução de si mesmo.

Partindo deste conjunto de premissas, nosso diálogo com a Pedagogia do Oprimido ressaltará a importância da superação da sociedade de classes. Objetivamos apontar para as possibilidades de negação da educação que nos torna, metaforicamente, docas incognoscentes que, cegos de um olho, impossibilita-nos de apreendermos a realidade multifacetada que nos rodeia. A justificativa para este ensaio encontra-se no próprio objetivo que intentamos percorrer, pois uma educação dentro dos parâmetros da sociedade de classes forma-nos, deforma-nos e especializa-nos com as mesmas tapas que se colocam nos cavalos que puxam "carretas": para que não sejamos capazes de ver nada ao redor; para que a nossa visão esteja fixada e atenta sempre à frente; para cumprirmos e obedecermos aos mandos e desmandos do capitalismo condutor da carruagem; para que continuemos a temer.

\section{PEDAGOGIA DO OPRIMIDO: PRIMEIRA APROXIMAÇÃO}

As afirmações que fazemos neste ensaio não são, de um lado, fruto de devaneios intelectuais nem, tampouco, de outro, resultam apenas de leituras, por mais importantes que elas nos tenham sido. Estão sempre ancoradas [...] em situações concretas (FREIRE, 2016, p. 55).

Para iniciarmos este capítulo, salientamos a principal característica da Pedagogia do Oprimido. Trata-se de uma pedagogia do oprimido e não para o oprimido. Esta ênfase é necessária para que possamos compreender que não existe a possibilidade de uma Educação promotora da emancipação e da autonomia dos sujeitos sociais oprimidos, quando seus objetivos não são por eles mesmo pensados, avaliados e definidos. Quando a educação é para o oprimido (por isto reportamo-nos sempre e uma vez mais à diferença já definida entre educação e Educação), as suas intencionalidades sociais (políticas, econômicas e culturais) têm uma matriz ideológica que não comunga com as verdadeiras necessidades deste grupo. Significa dizer, e assim defenderemos, que a Educação - com sentido de transformação, liberdade e emancipação dos humanos em suas múltiplas lateralidades - só existe se parte de quem dela necessita, ou seja, só haverá Educação quando os seus fundamentos, sentidos e sentimentos emanarem dos oprimidos (FIORI, 2014).

Outro importante elemento que merece destaque, outrossim pela atual conjuntura em que se encontra o Brasil, especialmente, é a declaração de que apenas dois segmentos sociais existem na sociedade de classes, isto é, a sociedade é distinta entre os opressores (classe dominante, proprietária dos meios materiais e espirituais de produção) e os oprimidos (classe dominada, expropriada em relações alienadoras de suas forças vitais). Embora esta pareça uma afirmação óbvia, ela serve para que, desde já, seja desmitificada a crença de que existe uma classe que subsiste entre os segmentos mencionados: a chamada "classe média".

A existência da "classe média" é uma ilusão. Serve aos opressores como acúmulo de pessoal e fortalecimento ideológico de um grupo sobre o outro. A inexistente "classe média" não passa de uma parcela da classe oprimida, sobre a qual o peso da opressão é aliviado pelo acesso a certos bens culturais e de consumo proibitivos à grande parcela dos oprimidos. De tal forma, a "classe média" se identifica com a ideologia dos opressores a ponto de professar a sua fé: insurgem-se contra os anseios mais genuínos da classe trabalhadora, entre outros, o de superar a situação de opressão, para assumirem a relações de exploração humanas como forma legítima e insuperável de reprodução 
social: a meritocracia e a falácia da igualdade de direitos faz do oprimido de "classe média" um opressor do seu igual.

Assim, paradoxalmente, o intento da falsa "classe média" é tornar-se grupo opressor, mas não se encontram organizados em nome de interesses comuns, como historicamente busca organizar-se a classe trabalhadora - ainda que ambos sejam os oprimidos. Nas palavras de Marilena Chaui (2013, p. 131), o imaginário da classe média "é povoado por um sonho e por um pesadelo: seu sonho é tornar-se parte da classe dominante; seu pesadelo é tornar-se proletária". Ainda nas palavras de Chaui (2013, p. 31, grifo da autora), o papel social e político da classe média, enquanto classe conservadora e reacionária, "é o de assegurar a hegemonia ideológica da classe dominante, fazendo com que essa ideologia, por intermédio da escola, da religião, dos meios de comunicação, se naturalize e se espalhe pelo todo da sociedade".

Dado o contexto acima descrito, a manutenção do imaginário, do sonho e do pesadelo da "classe média" dificulta a luta pela superação e a ruptura da sociedade de classes. Paulo Freire identificou que nos oprimidos sobrevive certa vontade e almejo de ocupar a posição de opressor, dando ênfase ao comportamento da "classe média", a exemplo do que descreve Marilena Chaui (2013).

Nas palavras de Freire (2014a, p. 68):

Há, [...] em certo momento da experiência existencial dos oprimidos, uma irresistível atração pelo opressor. Pelos seus padrões de vida. Participar destes padrões constitui uma incontida aspiração. Na sua alienação querem, a todo custo, parecer com o opressor. Imitá-lo. Segui-lo. Isto se verifica, sobretudo, nos oprimidos de "classe média", cujo anseio é serem iguais ao "homem ilustre" da chamada classe "superior".

Neste cenário, o papel da Educação figura como viabilidade de contextualização e de problematização da realidade na qual estamos imersos, dado que ninguém escapa dos processos educativos - no sentido em que definimos, na Introdução, Educação. Ainda, cabe reforçarmos que a atitude pedagógica no processo de Educação (que não se restringe as fronteiras da escola ou das instituições de ensino) deve estar pautado sob a égide da ética universal do ser humano.

A ética neoliberal, a ética do capitalismo ou a ética do mercado, são sinônimos de um mesmo ideal de exploração humana e, por esta razão, são incongruentes ao que chamamos de uma ética universal do ser humano. Outra postura ética que destoe da ética universal do ser humano só reforçará e alargará o abismo que divide opressores e oprimidos. A ética universal do ser humano deve ser posta de maneira inexorável por aqueles e aquelas que lutam pela libertação dos oprimidos e para a superação da sociedade de classes.

A ética de que nos fala Freire (2014b, p. 17), em suas palavras, é a seguinte:

[...] a ética de que falo não é a ética menor, restrita, do mercado, que se curva obediente aos interesses do lucro. [...]. Falo [...] da ética universal do ser humano [...], que condena a exploração da força de trabalho do ser humano, que condena [...] falsear a verdade, iludir o incauto, golpear o fraco e indefeso, soterrar o sonho e a utopia.

Os efeitos da ética do capitalismo, que nega as possibilidades do nosso "ser mais" (FREIRE, 2014a, 2014b), matam e freiam a vida, reduzem o ser humano à simples coisa alienada, e esta é a ética dos opressores (FREIRE, 2014a). Assim, é imprescindível que nos coloquemos a lutar juntos contra qualquer forma de opressão que negue o direito à vida, que seja promíscua com os seres humanos e suas necessidades vitais em nome do lucro. Daí deve emergir, naturalmente, a aliança consciente entre todos os oprimidos. "A luta", alerta-nos Freire (2006, p. 40), "já não se reduz a retardar o que virá ou a assegurar a sua chegada; é preciso reinventar o mundo. A educação é indispensável nessa reinvenção. Assumirmo-nos como sujeitos e objetos da História nos torna seres da decisão, da ruptura. Seres éticos". 
Assim, como defendeu Paulo Freire, acreditamos que as possibilidades da reinvenção do mundo estão, sobretudo, na Educação. A partir do momento em que nos colocamos como seres humanos sujeitos da história e, ao mesmo tempo, objetos dela, reconhecemos as possibilidades de transcendência da realidade que está posta pelos opressores como imutável e mecanicamente estagnada. É por esse motivo que apresentamos, a seguir, a Educação como uma das principais possibilidades da transformação social (econômica, política e cultural). A Educação como um locus de resistência à ética neoliberal, à exploração humana, ao mito do destino imutável e da história acabada.

\title{
3 A EDUCAÇÃO E A METÁFORA dA RAIZ PIVOTANTE
}

\begin{abstract}
É certo que a arma da crítica não pode substituir a crítica das armas, que o poder material tem que ser derrocado pelo poder material, mas também a teoria transforma-se em poder material logo que se apodera das massas. A teoria é capaz de apoderar-se das massas quando argumenta e demonstra ad hominem, e argumenta e demonstra ad hominem quando se torna radical; ser radical é tomar as coisas pela raiz. Mas a raiz, para o homem, é o próprio homem (MARX, 1977, p. 08).
\end{abstract}

Falar, ainda que metaforicamente, na comparação dialógica entre a Educação e as características de uma raiz pivotante é o caminho para exemplificarmos o potencial transformador que denota a Educação. Estamos nos referindo à Educação com potencialidade de transformação social (econômica, política e cultural), como o locus de resistência ao avanço das políticas neoliberais e das ideologias capitalistas. Significa, portanto, afirmar que não será a Educação, unicamente, a transformadora do status quo, mas esta será uma das principais figuras na abertura dos caminhos para a transformação possibilitada pela resistência e pela luta.

Geralmente, uma raiz está abaixo da superfície do solo. É a parte do vegetal responsável por fixá-lo, captar água e nutrientes necessários à vida deste ser vivo. A característica principal de uma raiz pivotante é o seu eixo principal, maior que os demais, que penetra profundamente no solo e dá as condições para que as outras partes da raiz, as raízes laterais, que não o eixo principal, desenvolvam-se. Para que seja possível a materialização da contingência da transformação social (econômica, política e cultural), partindo da ruptura com a sociedade de classes, metaforicamente, o eixo principal da raiz pivotante, que dará a sustentação e vida à uma sociedade sem classes deve ser, necessariamente, a Educação.

A Educação enquanto Formação Humana é feita pelos homens e pelas mulheres, somente por eles e elas, em suas relações sociais. Daí que, como disse Marx (1977, p. 08), representado na epígrafe, "a raiz do homem é o próprio homem". Aqui figura a Educação como locus de resistência por tratar de relações humanas. Acontece que não podem ser quaisquer relações humanas, dado que se assim o fosse não haveria necessidade de defendermos a mudança e a transformação. Assim, na Pedagogia do Oprimido, são imperativas as circunstâncias da emergência de relações humanizadas, pois a barbárie do capitalismo tem, há séculos, caminhado no rumo da desumanização do humano.

Fazendo eco ao que já falamos sobre a ética universal do ser humano, a Educação enquanto locus de resistência não pode significar outra coisa senão a capacidade e a possibilidade para o "ser mais" (FREIRE 2014a, 2014b). A ética do capital é incongruente à ética universal do ser humano porque promove o individualismo como modo de ser, limitando a liberdade destes, e impondo como intransponíveis as condições ideais para a concretização do estado existencial do ser menos. Ser mais é buscar a libertação e o desalojamento do opressor que vive arraigado no oprimido, ser menos é manter esta condição (des)humana. Ser mais é radicar a Educação como locus de resistência à situação existencial de ser menos e de luta contra a sociedade de classes, fazendo-se raiz pivotante que guia os processos sociais de subjetivação e de intersubjetividade da/na realidade/reinvenção do mundo, de si e do outro. 
A Educação embasada e amparada pelos anseios da teoria freireana, colocados na exposição da Pedagogia do Oprimido (e de outras obras), oferece-nos elementos para defendermos a história como algo não acabado, não determinado e não definitivo. É bem verdade que quando assumimos essa concepção de história temos que assumir, igualmente, que somos seres condicionados por ela, pois ela nos antecede; desde o nosso nascimento, adentramos em um mundo histórico pré-dado, posto que o encontramos tal como é. Disto ocorre que, no momento em que emergimos conscientes da condição humana de inacabamento, em um mundo também inacabado, admiramos o mundo histórico e passamos a ser construtores desta história que, anteriormente, fora elemento antecedente e que, agora, fazemos parte enquanto seres, igualmente, de possibilidades: compartilhamos com a história a analogia do inacabamento.

Assim, tomando como princípio ético para a Educação o inacabamento do ser e o inacabamento da história, as raízes laterais da sociedade poderiam apreender a totalidade do que significa este inacabamento. Este seria o primeiro passo para a não aceitação passiva da manipulação das massas: "A manipulação aparece como uma necessidade imperiosa das elites dominadoras" (FREIRE, 2014a, p. 199). Só com o reconhecimento de que vivemos em uma sociedade de classes, opressora e desigual é que podemos lutar contra a manipulação e a exploração: "O antídoto a esta manipulação está na organização criticamente consciente” (FREIRE, 2014a, p. 200). E a organização crítica necessita de um locus transformador, de um locus de resistência que, como ponto de partida, assume, entre outros: i) o princípio da ética universal do ser humano; ii) a necessidade da superação da sociedade de classes; iii) vida humana e história inacabadas, indeterminadas e de possibilidades infinitas.

Adentraremos, a seguir, nas considerações finais deste ensaio, contudo, não podemos dizê-las considerações finais e acabadas, pois conscientes do inacabamento do ser, somos impossibilitados de crer em um fundamento último para uma discussão tão ampla. Evidenciaremos nossa repulsa a qualquer crença antidialógica e pessimista que negue a possibilidade de uma reinvenção da sociedade e do mundo por nós, seres humanos inacabados.

\section{CONSIDERAÇÕES FINAIS}

O que nos parece indiscutivel é que, se pretendemos a libertação dos homens, não podemos começar por aliená-los ou mantê-los alienados. A libertação autêntica, que é a humanização em processo, não é uma coisa que se deposita nos homens. Não é uma palavra a mais, oca, mitificante. É práxis, que implica a ação e a reflexão dos homens sobre o mundo para transformá-lo (FREIRE, 2013, p. 93).

Como afirmamos algures, o pressuposto para que a radicalidade da mudança seja possível deve ser assegurada pela consciência coletiva de que vivemos em uma sociedade de classes. Como já o fazem, os opressores buscarão pregar a harmonia social (econômica, política e cultural) e, igualmente, almejarão o silêncio dos oprimidos pela dinâmica de aliená-los. Com o silêncio dos oprimidos, os opressores vivem tranquilamente. Em silêncio, os oprimidos não conseguem admirar o mundo, olhá-lo de dentro, participar democraticamente dos acontecimentos sociais. Por isso, não podemos deixar de falar sobre a importância do diálogo aos oprimidos, da necessidade de dizerem as suas palavras e fazerem as suas reivindicações.

A existência, porque humana, não pode ser muda, silenciosa, nem tampouco pode nutrir-se de falsas palavras, mas de palavras verdadeiras, com que os homens transformam o mundo. Existir, humanamente, é pronunciar o mundo, é modificá-lo. O mundo pronunciado, por sua vez, se volta problematizado aos sujeitos pronunciantes, a exigir deles novo pronunciar (FREIRE, 2014a, p. 108, grifo do autor). 
Aos opressores não importa a dialogicidade da vida, do quefazer humano. Os dominadores perpetuam seus ideais por meio de ações antidialógicas. Daí que a autêntica Educação pressupõe diálogo, abertura ao outro, reconhecimento, escuta atenta e prestativa. Nisso reside a crítica combativa à educação ocupada com o treinamento técnico e a preparação instrumental, unicamente, para o mundo do trabalho alienado. Os fundamentos éticos da ação dialógica presentes na Pedagogia do Oprimido são um dos caminhos para o desvelamento da realidade, da situação de opressão em que nos encontramos em grande maioria.

O eu dialógico [...] sabe que é exatamente o tu que o constitui. Sabe também que, constituído por um $t u$ - um não eu -, esse $t u$ que o constitui se constitui, por sua vez, como $e u$, ao ter no seu eu um $t u$. Desta forma, o eu e o $t u$ passam a ser, na dialética destas relações constitutivas, dois $t u$ que se fazem dois eu (FREIRE, 2014a, p. 227, grifo do autor).

Nessa relação de reconhecimento do outro é que pode acontecer a libertação dos seres humanos. Aqui, a palavra libertação deve ser entendida e assumida como sinônimo de emancipação, já o sentido da emancipação pressupõe o conhecimento das condições materiais e espirituais do sujeito oprimido e do seu outro. Assim, liberdade e emancipação compreendem o saber-se inacabado e inconcluso, o (re)conhecer-se como sujeito de possibilidades, de múltiplos caminhos para o vir-a-ser histórico daquilo que se deseja ser, mediado pela dialógica da convivência humana. Em outra lógica, ou seja, na tendência antidialógica, o opressor transforma o tu em coisa, em mão-de-obra, em objeto, em mercadoria no mundo do trabalho a ser explorada. Volta-se à lógica do sujeito e do objeto, onde o sujeito domina o objeto. Na relação antidialógica o opressor é o sujeito e o oprimido o objeto, e o objeto humano, desumanizado e tratado como coisa, é sempre manipulado em nome dos interesses da ética do capitalismo: a coisificação do ser humano precede o ser menos. Porém, é a ação dialógica que permite aos oprimidos desmitificar o mundo velado, dito acabado e estático pela elite opressora. $\mathrm{O}$ eu dialógico precede o ser mais.

Se tomamos a Educação como o locus de resistência, é porque este é o lugar do reconhecimento dos antagonismos sociais que, constituindo-nos, por vezes, constituímos e reproduzimos. Portanto, resistir é uma forma de (re)inventarmos o mundo à medida em que, rechaçando a adaptação ao sistema projetado para o oprimido pelo opressor, identificamos as antinomias entre a luta de classes e a formação humana. Resistir é reconhecer o antagônico e não se curvar docilmente a ele. Para Paulo Freire (2014a), uma adaptação às condições impostas pelo opressor só pode ser aceita enquanto se espera pelo momento propício à luta entre os antagônicos.

$\mathrm{Na}$ Pedagogia do Oprimido estão vivos e renovados os ideais de luta e de resistência à barbárie do capitalismo. É por isto que esperamos que os interlocutores deste ensaio encontrem provocações ao pensamento em nome daquilo que representa as aspirações possíveis do ser mais, na união, na emancipação e na libertação coletiva dos seres humanos, superando a sociedade de classes desde uma Educação como locus de Formação Humana para a resistência aos mandos e aos desmandos do opressor. 


\section{REFERENCIAS}

BRANDÃO, Carlos Rodrigues. O que é Educação Popular? São Paulo: Brasiliense, 2006.

CHAUI, Marilena. Uma nova classe trabalhadora. In: SADER, Emir (org.). 10 anos de governos pós-neoliberais no Brasil: Lula e Dilma. São Paulo: Boitempo, 2013.

FIORI, Ernani Maria. Prefácio. Aprender a dizer a sua palavra. In: FREIRE, Paulo. Pedagogia do oprimido. São Paulo: Paz e Terra, 2014a.

FLEURI, Reinaldo Matias. Educar para quê? - Contra o autoritarismo da relação pedagógica na escola. São Paulo: Cortez, 1989.

FREIRE, Paulo. A sombra desta Mangueira. São Paulo: Olho d’Água, 2006.

FREIRE, Paulo. Pedagogia do oprimido. São Paulo: Paz e Terra, 2013

FREIRE, Paulo. Pedagogia do oprimido. São Paulo: Paz e Terra, 2014a.

FREIRE, Paulo. Pedagogia do oprimido. São Paulo: Paz e Terra, 2016.

FREIRE, Paulo. Pedagogia da autonomia: saberes necessários à prática educativa. São Paulo: Paz e Terra, $2014 \mathrm{~b}$.

MARX, Karl. Crítica da filosofia do direito de Hegel - Introdução. In: Temas de ciências humanas. Vol. 2. São Paulo: Editorial Grijalbo, 1977.

PALUDO, Conceição. Educação Popular em busca de alternativas: uma leitura desde o campo democrático e popular. Porto Alegre: Tomo Editorial, 2001.

PONTUAL, Pedro Pontual; IRELAND, Timothy (Orgs.). Educação Popular na América Latina: diálogos e perspectivas. Brasília: Ministério da Educação: UNESCO, 2006.

STRECK, Danilo; ESTEBAN, Maria Teresa (Orgs.). Educação Popular: Lugar de construção social coletiva. Petrópolis: Vozes, 2013.

\begin{tabular}{|ll} 
Histórico & Recebido em: 04/06/2016 \\
& Revisado em: 18/06/2017 \\
& Aceito em: 09/05/2019 \\
& Concepção: FVA; JGN; ANP; TLP; RGC \\
Contribuição & Elaboração do manuscrito: FVA; JGN; ANP; TLP; RGC \\
& Revisões críticas de conteúdo intelectual importante: FVA; JGN; ANP; TLP; RGC \\
& \\
& Filipi Vieira Amorim e Alana das Neves Pedruzzi - bolsas CAPES - Programa de Pós- \\
& Graduação em Educação Ambiental - PPGEA da Universidade Federal do Rio Grande - \\
& FURG; Júlia Guimarães Neves - bolsa CAPES - Programa de Pós-Graduação em Educação \\
& - PPGE da Universidade Federal de Pelotas - UFPEL e Tamires Lopes Podewils - bolsa \\
& CNPq - Programa de Pós-Graduação em Educação Ambiental - PPGEA da Universidade \\
& Federal do Rio Grande - FURG. \\
&
\end{tabular}

